(2) Open Access Full Text Article

REVIEW

\title{
A review of the epidemiology and treatment of Peyronie's disease
}

This article was published in the following Dove Press journal:

Research and Reports in Urology

29 April 2016

Number of times this article has been viewed

\section{Kevin A Ostrowski \\ John R Gannon \\ Thomas J Walsh \\ Department of Urology, University of Washington, Seattle, WA, USA}

Correspondence: Thomas JWalsh

Department of Urology, University of

Washington, 1959 NE Pacific Street,

BB-I I I , Box 3565 I0, Seattle,

WA 98195 , USA

Tel + I 206685 I982

Fax +I 2065433272

EmailWalsht@uw.edu
Introduction: Peyronie's disease (PD) has significant effect on patients and their partners. We provide a current review of the epidemiology as well as the nonsurgical and surgical treatment of PD.

Materials and methods: Review of literature pertaining to PD with focus on epidemiology and treatment options.

Conclusion: PD is common and likely underreported. The availability of new and highly effective treatment options will catalyze patient awareness and subsequently the prevalence of disease.

Keywords: Peyronie's disease, erectile dysfunction, review

\section{Introduction}

Peyronie's disease (PD) is caused by progressive fibrosis of the tunica albuginea of the corpora cavernosa resulting in curvature or other deformities of the erect penis. The severity of penile curvature or other deformities may contribute to a man's inability to have intercourse (sexual disability). This sexual disability can be due to difficulty with penetration, partner pain, or emotional stress. This review evaluates the epidemiology, natural history, and nonsurgical and surgical treatments of PD.

\section{Anatomy and pathophysiology of PD}

The tunica albuginea of the penile corpus cavernosum is composed of interwoven elastic and collagen fibers. This tissue is bilaminar with an inner circular and outer longitudinal layer. During a normal penile erection, stimulation causes release of nitric oxide that increases penile blood flow and relaxes cavernosal smooth muscle. This increase in cavernosal hydrostatic pressure eventually leads to compression and occlusion of the small venules that perforate the tunica albuginea. Scanning electron microscope evaluation of PD plaques shows a loss of normal collagen architecture within the tunica, with excessive collagen I and III deposition and disordered fibrin and elastic fibers. The deposition of scar tissue within the tunica albuginea diminishes its elasticity, subsequently limiting normal stretch and causing penile curvature. ${ }^{1}$

The etiology of PD is not completely understood but is thought to be due to trauma or microtrauma to the tunica albuginea combined with a disorder of wound healing. Trauma, primarily during intercourse, may result in subtle delamination of the tunica, bleeding, and clot formation. Degradation of fibrin within the clot may foster improper signaling by growth factors, such as transforming growth factor (TGF)- $\beta 1$, fibrin, and 
plasminogen activator inhibitor-1. This improper signaling causes scarring of the inner lamina leading to plaque formation and subsequent curvature. ${ }^{2}$

TGF- $\beta 1$ is a profibrotic factor activating collagen I synthesis and is released by neutrophils and macrophages during the acute and proliferative phases of wound healing. Peyronie's plaques have been shown to have overexpression of TGF- $\beta 1$ without subsequent increase in TGF- $\beta 2$ or TGF$\beta 3$ suggesting TGF- $\beta 1$ role in $\mathrm{PD} .^{3}$

\section{Epidemiology}

Contemporary scientific literature suggests markedly variable rates of PD based on country of origin. The prevalence of PD is reported to be between $0.4 \%$ and $3.2 \%$ of men in the United States. ${ }^{4-6}$ In a Japanese study in 2012, there is a low rate, $0.6 \%$ of men reporting PD. ${ }^{7}$ A larger rate of PD (7.1\%) was found in a survey study of Italian men. ${ }^{8}$ In a large questionnairebased study from Germany, 2.7\% of the 4,432 respondents had a palpable plaque and curvature. The prevalence of PD increased with age in an additional study, with only $1.5 \%$ of men 30-39 years old reporting PD versus $6.5 \%$ of men $>70$ years. ${ }^{4}$ Most likely, these rates are underestimates due to patient's failure to seek evaluation and treatment due to embarrassment from their condition. In a cohort of 534 men screened for PD at the time of prostate cancer evaluation, Mulhall et al found that $6 \%$ of the patients reported penile curvature and $8.9 \%$ had a penile plaque on physical examination. Further, the occurrence of Peyronie's plaque was more common in men with diabetes mellitus, hypertension, lower sexual health index in men scores, and increasing age. ${ }^{9}$

Multiple studies have evaluated risk factors associated with PD, such as age,${ }^{10}$ diabetes,${ }^{4,9,11,12}$ smoking, ${ }^{8,11}$ Caucasian descent, ${ }^{13}$ and genetic predisposition. ${ }^{11,14,15}$ Increasing age and trauma have been shown to be risk factors for PD in multiple studies. ${ }^{10}$ Diabetes is associated with both PD and more severe curvature. ${ }^{12}$ There is also evidence of a genetic predisposition leading to the formation of Peyronie's plaque as up to $20 \%$ of patients with PD have Dupuytren's contracture of the tendons in their hand and up to $9 \%$ of men with PD will have a family member with Dupuytren's contraction. ${ }^{14}$ Other multiple clinical characteristics, including hypertension, hyperlipidemia, coronary artery disease, alcohol use, sexually transmitted disease, and urologic surgery history, have been evaluated and have no consistent association with PD. ${ }^{8,11}$

\section{Psychological effects of PD}

PD has been associated with negative psychological effects on patients. Nelson et $\mathrm{al}^{16}$ evaluated 92 men with PD for clinical depression and found that $48 \%$ of men with PD experienced clinical depression independent of disease duration. Smith et al reported similar results. They found that the prevalence of emotional and relationship problems attributable to PD were $81 \%$ and $54 \%$, respectively. Multivariable analysis revealed that emotional difficulties and ability to have intercourse were independently associated with relationship problems after adjusting for the ability to maintain an erection. ${ }^{17}$ In recent years, a 15-question PD-specific questionnaire has been validated for use in the assessment of patients. This has been used in studies and will in the future allow for further objective PD research. ${ }^{18}$

\section{Natural history and associations with erectile dysfunction}

Mulhall et al evaluated the natural history of PD without treatment. In this study, 246 men who presented within 6 months of disease onset were followed for at least 12 months from disease onset (mean duration of PD: 18 months \pm 7 months). At baseline, $72 \%$ reported dorsal curvature, $17 \%$ ventral, and $11 \%$ lateral. Mean curvature in this population was $42^{\circ} \pm 22^{\circ}$. All patients initially presenting with penile pain had improvement, with nine of ten patients reporting complete resolution. One-third of the patients complained of erectile dysfunction at baseline. Eight-four percent reported a subjective loss of stretched penile length at follow-up. Comparing the patients later, from their initial presentation, $12 \%$ had improvement of their curvature, $40 \%$ remained stable, and $48 \%$ reported worsening of their curvature. ${ }^{19}$

Erectile dysfunction is present in $20 \%-50 \%$ of men with PD and occurs from a variety of reasons including deformity preventing coitus, flail penis (cavernous fibrosis or vascular compromise), performance anxiety (psychological), or impaired erections caused by veno-occlusive dysfunction. ${ }^{19}$ Veno-occlusive dysfunction is due to the impaired ability of the tunica to expand and accommodate increased blood inflow as a result of the scarring. This results in the failure of occlusion of the subtunical venules combined with impaired cavernosal arterial inflow. ${ }^{20}$ The quality of life of the patients and partners is significantly impacted as men with PD are at increased risk of depression, lowered self-esteem, and relationship difficulties, in addition to body image issues and pain. Psychological manifestations have been underelucidated traditionally by urologists and primary care practitioners and represent a significant aspect of the burden of PD. ${ }^{19}$

\section{The treatment of PD}

The treatment options for PD are highly varied, ranging from oral therapies to traction, injections, and surgeries. Few treatments have had their efficacy confirmed by randomized 
controlled trials. The goals of treatment are improvement in penile deformity, improvement in sexual function, and improvement in quality of life. Further, the treatment of PD should attempt to address the physical and psychological ramifications of the disease.

\section{Medical therapy}

Table 1 summarizes the oral therapies that have been described to treat PD.

\section{Pentoxifylline}

Pentoxifylline's mechanism of action in the treatment of PD is unknown, but it is believed to block collagen type I deposition and TGF- $\beta 1$, which in animal models has been linked to be a causative agent of PD. ${ }^{21}$ It additionally does appear to have some effect as a nonspecific phosphodiesterase inhibitor increasing penile blood flow. The efficacy of pentoxifylline has been evaluated in two double-blinded, placebo-controlled studies. These studies evaluated 228 patients, whereby pentoxifylline $400 \mathrm{mg}$ was given twice daily and compared with placebo. These patients were followed for 6 months via examination, ultrasonography, and by validated questionnaires regarding erectile function and treatment satisfaction. There was a mean reduction in curvature $\left(-22^{\circ}\right.$ in dorsal curvature) compared to an increase in curvature in the placebo group. In addition, improvement was noted in lateral and ventral curvature. In addition to penile curvature, plaque size, erectile function, and blood flow as measured by peak systolic velocity improved in those taking pentoxifylline compared to placebo. 22,23 The 2010 study was recently retracted from the British Journal of Urology International due to statistical concerns that do call into question some of the evidence for this medication. In a third, nonrandomized study, pentoxifylline was compared to oral vitamin E treatment. In this study, there was a statistically significant improvement in ultrasound characteristics of the plaque in those using the pentoxifylline compared to vitamin E, 99\% versus $44 \%$ improvement, respectively. ${ }^{24}$ Pentoxifylline is approved by the Food and Drug Administration for the treatment of claudication of the lower extremities; therefore, patients should be informed that its use in PD is "off label." The most common side effects are nausea, vomiting, or gastroesophageal reflux symptoms. Taking the medication with meals can alleviate many of these symptoms. This medication was not evaluated or commented on in the recent 2015 American Urological Association (AUA) guidelines regarding PD. ${ }^{25}$

\section{Vitamin E}

Vitamin E is a potent antioxidant that is thought to reduce collagen deposition in scar formation. While it is widely used, there is little evidence of superiority when compared to placebo. ${ }^{26}$ There are a total of seven studies on the effects of vitamin $\mathrm{E}$. In a randomized, double-blind trial involving 236 men, vitamin E did not significantly improve curvature or plaque size. Vitamin $\mathrm{E}$ alone or in combination with carnitine showed no significant improvement in any outcome measures. ${ }^{26}$ Another observational study by Inal in $2006^{27}$ found that patients using vitamin $\mathrm{E}$ had worsening of their curvature and plaque. In contrast to the results of the prior studies, vitamin E did show improvement when combined

Table I Oral treatment of Peyronie's disease

\begin{tabular}{|c|c|c|c|c|}
\hline Medication & Mechanism of action & Data supporting & AUA guidelines & Side effects \\
\hline Pentoxifylline & $\begin{array}{l}\text { Unknown, presumed } \\
\text { collagen inhibition }\end{array}$ & $\begin{array}{l}\text { Two RCTsa, one observational } \\
\text { study showing improvement }\end{array}$ & No comment & Gastrointestinal reflux \\
\hline Vitamin E & $\begin{array}{l}\text { Antioxidant, inhibits } \\
\text { collagen deposition }\end{array}$ & $\begin{array}{l}\text { Seven trials; three RCTs, } \\
\text { observational studies with } \\
\text { additional medications }\end{array}$ & Not recommended & $\begin{array}{l}\text { Mild, can affect other } \\
\text { concurrent medications } \\
\text { metabolism }\end{array}$ \\
\hline Potaba & $\begin{array}{l}\text { Decrease tissue serotonin } \\
\text { levels and scarring }\end{array}$ & One RCT & No comment & $\begin{array}{l}\text { Very expensive, frequent } \\
\text { dosing, nausea, fever, rash }\end{array}$ \\
\hline Colchicine & $\begin{array}{l}\text { Unknown, inhibits collagen } \\
\text { synthesis }\end{array}$ & $\begin{array}{l}\text { One RCT which showed no } \\
\text { effect, one with vitamin E }\end{array}$ & No comment & $\begin{array}{l}\text { Nausea, gastrointestinal } \\
\text { reflux }\end{array}$ \\
\hline Tamoxifen & Unknown, reduces fibrosis & Two observational, one RCT & Not recommended & Minimal \\
\hline Carnitine & Inhibits free radicals & $\begin{array}{l}\text { Multiple observational, often } \\
\text { with other medications }\end{array}$ & Not recommended & Minimal \\
\hline Coenzyme QI0 & Antioxidant & One RCT & No comment & Minimal \\
\hline Procarbazine & $\begin{array}{l}\text { Antineoplastic agent, } \\
\text { inhibits protein, DNA, } \\
\text { RNA synthesis }\end{array}$ & Observational & Not recommended & $\begin{array}{l}\text { Potentially severe side } \\
\text { effects }\end{array}$ \\
\hline Omega-3 fatty acids & $\begin{array}{l}\text { Inhibits inflammatory } \\
\text { cytokines }\end{array}$ & Limited observational & Not recommended & Minimal \\
\hline
\end{tabular}

Note: ${ }^{2} 2010 \mathrm{RCT}^{23}$ recently retracted due to statistical concerns.

Abbreviations: RCT, randomized controlled trial; AUA, American Urological Association. 
Table 2 Intralesional injections

\begin{tabular}{|c|c|c|c|c|}
\hline Medication & Mechanism of action & Data supporting & AUA guidelines & Side effects \\
\hline Intralesional interferon & $\begin{array}{l}\text { Decrease fibroblast } \\
\text { proliferation }\end{array}$ & $\begin{array}{l}\text { One RCT (multi-institutional), } \\
\text { eight observational studies }\end{array}$ & $\begin{array}{l}\text { Recommended when } \\
\text { appropriate }\end{array}$ & $\begin{array}{l}\text { Flu-like symptoms, rash, } \\
\text { hypotension }\end{array}$ \\
\hline Intralesional verapamil & $\begin{array}{l}\text { Decrease collagen } \\
\text { deposition }\end{array}$ & $\mathrm{RCT}$, observational & $\begin{array}{l}\text { Recommended when } \\
\text { appropriate }\end{array}$ & $\begin{array}{l}\text { Bruising, nausea, } \\
\text { dizziness }\end{array}$ \\
\hline Intralesional collagenase & Cleavage of collagenase & $\begin{array}{l}\text { Four RCTs; IMPRESS I, II, } \\
\text { observational study }\end{array}$ & $\begin{array}{l}\text { Recommended when } \\
\text { appropriate }\end{array}$ & $\begin{array}{l}\text { Hematoma, bruising, } \\
\text { corporal rupture }\end{array}$ \\
\hline
\end{tabular}

Abbreviation: RCT, randomized controlled trial.

with colchicine. A trial of 45 men treated with a combination of vitamin $\mathrm{E}$ and colchicine or ibuprofen found no improvement in pain related to their Peyronie's plaque. ${ }^{28}$ Given these unclear results, the AUA panel did not recommend vitamin $\mathrm{E}$ use for the treatment of PD. ${ }^{25}$

\section{Potaba}

Potassium para-aminobenzoate (Potaba) is an antifibrotic agent that is thought to increase tissue levels of monoamine oxidase, decreasing the level of serotonin that contributes to scar formation in PD. In a 1-year placebo-controlled trial, involving 103 men with known PD, select patients were given $3 \mathrm{~g}$ of Potaba four times a day. Seventy-four percent of those in the treatment group (compared to $50 \%$ in the placebo group) responded with a reduction in the plaque size or a decreased penile curvature of up to $30 \%{ }^{4,29}$ Potaba is an expensive medication, with a large and frequent dosing regimen, leading to significant patient expense. Potaba was not commented on or assessed in the recent AUA 2015 guidelines. ${ }^{25}$

\section{Colchicine}

Colchicine inhibits collagen synthesis and fibrosis. Observational studies conducted by placing patients on colchicine showed improvement in penile pain and curvature..$^{30,31}$ A randomized, placebo-controlled trial, with 78 patients, did not demonstrate difference in plaque size or curvature for those using colchicine. Colchicine was found as effective in men with mild curvature when used with vitamin $\mathrm{E}$, in a study of 45 men as mentioned previously. ${ }^{28}$ Colchicine, like Potaba and pentoxifylline, has been linked to gastrointestinal side effects; additionally, it has also been shown to suppress bone marrow function. ${ }^{30,31}$ Given its risk for bone marrow suppression and little supporting evidence of its beneficial effect, colchicine was not recommended as a monotherapy in the AUA guidelines. ${ }^{25}$

\section{Tamoxifen}

Tamoxifen is a well-known agent approved by the US Federal Drug Administration (FDA) as an estrogen receptor blocker for the treatment of hormone receptor-positive breast cancer. Three studies have been published regarding tamoxifen's effects on PD. In a 25-patient randomized, double-blind trial of tamoxifen compared to placebo in 1999, there was no statistically significant difference with regard to correction of the curvature when comparing the two groups, with each group showing mild improvement. ${ }^{31}$ The AUA 2015 guidelines on PD do not recommend the use of tamoxifen for the treatment of PD. ${ }^{25}$

\section{Carnitine}

Carnitine acts an acetyl coenzyme-A inhibitor inhibiting free radicals. Trials have shown variable results with the use of carnitine in the treatment of PD. Trials comparing carnitine to tamoxifen showed greater improvement of curvature in the carnitine group $\left(16^{\circ}\right.$ vs $8^{\circ}$, respectively). ${ }^{33}$ In another previously mentioned trial, carnitine alone or in combination with vitamin $\mathrm{E}$ did not show a significant improvement in curvature or plaque size. ${ }^{26} \mathrm{An}$ additional trial of 60 patients was treated with intralesional verapamil and given oral tamoxifen or carnitine. In those treated with oral carnitine in addition to intralesional therapy, there was a statistically significant improvement in penile curvature, $12^{\circ}$ compared to $2^{\circ}$, and plaque size reduction, $\sim 8 \mathrm{~mm}$ compared to $\sim 1 \mathrm{~mm} .{ }^{34}$ The AUA 2015 guidelines do not recommend the use of carnitine in the treatment of PD as there was no clear evidence linking improvements to carnitine monotherapy. ${ }^{25}$

\section{Coenzyme Q10}

Coenzyme Q10, a vitamin-like quinone, is a powerful antioxidant. It is presumed to help generate further antioxidants inhibiting inflammation and scarring. In a randomized, placebo-controlled trial, with 186 patients, those using Q10 were shown to have statistically significant improvement in curvature, plaque size, and International Index of Erectile Function score. ${ }^{35}$

\section{Procarbazine and omega-3 fatty acids}

Procarbazine and omega-3 fatty acids have each been studied in small trials, neither have been linked to improvement in 
curvature when compared to placebo and therefore are not recommended for the treatment of PD. ${ }^{25}$

\section{Injection therapy Interferon alpha $2 b$}

Interferon (IFN) intralesional injection was first examined in 1991. Table 2 summarizes the injection therapies that have been described to treat PD. IFN targets fibroblast proliferation involved in plaque formation. ${ }^{36,37}$ IFN injections are typically performed, biweekly over a 6-week period. ${ }^{37}$ IFN has been evaluated in one large randomized controlled trial and eight observational studies. Significant improvements in curvature (average $13.5^{\circ}$ ) were seen in patients treated with IFN injections compared with saline in the randomized controlled trial involving 117 patients. ${ }^{37}$ In a second followup study with 127 patients, undergoing either one cycle or two cycles (12 injections per cycle), 54\% of the patients experienced $20 \%$ or greater improvement in curvature with a total average improvement of $9^{\circ}$. Although not statistically significant, there was a trend for those with greater curvature to have more improvement overall. ${ }^{38}$ IFN at higher doses than those studied has been linked with some severe side effects including a flu-like illness, anorexia, rash, hypotension, and possible cardiac arrhythmias. ${ }^{36}$ The AUA recommended using this medication in appropriate settings. ${ }^{25}$

\section{Calcium channel blockers}

Intralesional verapamil and other calcium channel blockers were initially introduced in 1994. Verapamil has been shown in in vitro studies to decrease platelet-derived growth factorbeta-dependent collagen deposition. ${ }^{9,39,40-42}$ Additional studies have shown a decrease in early-phase fibroblast proliferation associated with the development of Peyronie's plaque. , $^{9,40}$ Verapamil is typically delivered into the lesion twice weekly for 12 weeks. $^{42}$

Verapamil has been evaluated in nine prospective trials, eight observational studies, and two randomized controlled trials. These trials have not been uniform with variation in dosing of the medication or other oral agents used as adjuvant therapy. Nonetheless, the majority of these trials have shown improvement in plaque size and curvature as well as symptoms (pain). In four prospective studies, one of which was a randomized, placebo-controlled trial, there was a benefit in curvature, plaque size, and penile pain. ${ }^{34,43}$ The AUA recommended the use of this medication in appropriate settings to treat PD.

\section{Intralesional collagenase}

Intralesional collagenase injections have been discussed since the 1980s for the treatment of PD. Collagenase Clostridium histolyticum $(\mathrm{CCH})$, a current collagenase, is typically given during two injection appointments and one modeling appointment in the span of 1 week. CCH mechanism of action is by the cleavage of the triple helix of the collagen fibrils, primarily collagen types I and III, the primary collagen within a Peyronie's lesion. The active metabolic agents in $\mathrm{CCH}$ are AUX I and II. The collagenase is used from Clostridium rather than a mammalian source as this cleavage occurs at multiple sites along the collagen chain rather than just at one site. ${ }^{44}$

A total of four randomized trials have been conducted, one in 1993 and three in 2012. In 2013, the US FDA approved the use of $\mathrm{CCH}$ after two, Phase III randomized controlled trials, IMPRESS I and II, showed the safety and efficacy of this medication in the treatment of PD. ${ }^{44}$ To date, this is the first and only medication US FDA approved for the treatment of a Peyronie's lesion. A subsequent open-labeled follow-up trial by Levine et $\mathrm{al}^{45}$ showed an average improvement of penile curvature of $\sim 20^{\circ}(34 \%)$ in $>600$ patients; this result mirrored the findings in the initial IMPRESS studies. ${ }^{44}$ In addition to a statistical significant improvement in the degree of curvature, each study has shown improvement in PD bother score.

It is important to acknowledge that there were adverse treatment-related events in nearly $85 \%$ of the subjects participating in the study, the vast majority of these episodes being related to local bruising, hematoma, or pain at the injection site. In the follow-up study of Levine et $\mathrm{al}^{45}$ of 347 patients, only three significant patient-related events occurred with one corporal rupture and two penile hematomas. ${ }^{44}$ Based on the findings of the IMPRESS studies, the AUA guidelines recommended the use of this medication in appropriate settings for the treatment of PD.

\section{Traction therapy}

The use of traction therapy for the treatment of PD is well established and is thought to work via mechanical stretching and subsequent plaque remodeling. The treatment can be cumbersome as the device must be worn daily and for prolonged periods of time. The first study involved ten patients wearing the device for a minimum of 2 hours daily. In this small observational study, all patients were found to have a reduction in penile curvature with an average decrease of $33 \%$ as well as an increase in penile length. ${ }^{46}$ This therapy has been used as a neoadjuvant and adjuvant treatment along with other therapies for PD, including intralesional injection and oral medical therapy. A recent study evaluated the use of traction therapy for 3 hours on patients undergoing intralesional IFN injections; the use of traction therapy for 3 or more hours daily showed a significant improvement in stretched penile length 
compared to those not using traction therapy $(+4.4 \mathrm{~mm}$ vs $+1.3 \mathrm{~mm}, P=0.04$ ) (Yafi et al, 2015). ${ }^{47}$ The 2015 guidelines did not comment on traction therapy.

\section{Vacuum therapy}

Similar to traction therapy, vacuum erection devices have been investigated as a treatment for PD, especially due to their advantage of providing radial stretch. A small case series of 31 patients was studied in $2010 .{ }^{48}$ These patients were instructed to perform two 10-minute sessions daily, using a vacuum pump device for 12 weeks. Of the 31 patients studied, $90 \%$ reported a decrease, or stable curvature, with additional improvements in penile pain and reported an increase in length. ${ }^{48}$ The guideline panel did not comment on vacuum erection device treatment.

\section{Iontophoresis}

Iontophoresis has also been known as electromotive drug administration. It is a noninvasive method of drug delivery. In this therapy, a small electric charge is used to deliver a medication transdermally. Prior studies have suggested that transdermal treatments do not show adequate penetration of transdermally applied verapamil. ${ }^{42,49}$ In a 42-patient, randomized, placebo-controlled trial in 2003, patients underwent semi-weekly treatment of either verapamil $(10 \mathrm{mg})$ in saline or just saline delivered by iontophoresis for 20 minutes for a period of 3 months. ${ }^{49}$ In this 2003 study conducted by Greenfield, there was a mean improvement of $9^{\circ}$ in $65 \%$ of the patients receiving verapamil; however, this was not statistically significant as $58 \%$ of the placebo control group had a mean improvement of $\sim 7.5^{\circ} .{ }^{49}$ Because of this equivocal result, the AUA guideline panel in 2015 did not recommend this treatment.

\section{Extracorporeal shock wave lithotripsy}

Extracorporeal shock wave lithotripsy (ESWL) was first described in the treatment of PD in 1996. ESWL therapy delivers directed shocks to the plaque, causing plaque damage, absorption, and increased vascular in growth to the tissue. ${ }^{42,50}$ A meta-analysis of 17 studies showed improvement in patient-measured, sexual and erectile function as well as pain. ${ }^{50}$ However, this meta-analysis did not show improvement in plaque size or curvature. A randomized controlled trial was conducted in 2009 with 100 participants. These patients were randomized to 4 weeks of ESWL therapy or a nonfunctional transducer acting as a placebo. ${ }^{51}$ As seen in the earlier meta-analysis study, there was improvement in pain, erectile function, and other subjective measures; however, there was no statistically significant improvement in plaque size or curvature. ${ }^{50} \mathrm{~A}$ consensus statement by the International Consultation on Sexual Medicine in 2010 and the AUA guideline in 2015 support the role of ESWL therapy for the treatment of Peyronie's related pain; however, there has been no support for the use of this therapy in the treatment of curvature or plaque size. ${ }^{25,42,52}$

\section{Surgical therapy}

The use of surgery to straighten the penis is well established. Depending on the severity of a patient's disease and presentation, different surgical approaches are more or less likely to be successful. ${ }^{53}$ Prior to selecting an appropriate surgical approach, the characteristics of a patient's erection should be thoroughly assessed. This should include a patient's stretched penile length, erectile function/rigidity, degree of curvature, the presence or absence of hinging, and the presence of an hourglass narrowing. ${ }^{53,54}$ This assessment can be done in clinic through physical examination and duplex ultrasonography after inducing an erection. ${ }^{54}$

Whether a patient has sufficiently rigid erections for penetrative intercourse is a critical factor in selecting a surgical technique. ${ }^{53}$ If there is moderate-to-severe erectile dysfunction associated with the patient's $\mathrm{PD}$, the patient may benefit more from surgery that corrects both erectile dysfunction and PD, like the placement of a penile prosthesis. Universally, nonprosthetic surgical options for PD will not improve erectile function and may lead to worsening function in some cases. Further, before consideration of surgery, the patient should have stable, nonpainful disease for at least 6 months, with the onset of disease at least 1 year prior. ${ }^{52-54}$

\section{Tunical "corporoplasty" procedures}

Penile plication has been described in a variety of surgical techniques. Plication may be performed in an excisional manner on the noncontracted side as initially described by Nesbit. ${ }^{55}$ Additional excision procedures have been described such as the Yachia procedure, where a vertical incision is closed in a horizontal (Heineke-Mikulicz) fashion. ${ }^{56}$ The benefit of these procedures is the placement of absorbable sutures in the closure of the corporal body.

In addition to an excisional shortening of the healthy, unaffected corporal, a second popular technique is shortening of the corporal body in a "folding" manner, commonly called a 16-dot plication. This shortening of the tunica in a Lembert-type manner relies upon permanent sutures. ${ }^{57,58}$ Plication through excision or Lambert means seeks to shorten the healthy corporal body and may lead to perceived penile 
shortening. The degree of shortening is related to the degree of curvature..$^{59}$ This procedure should be performed with an artificial erection obtained either by the aid of intracorporal injection or by the normal saline instillation.

Straightening occurs in almost $100 \%$ of cases; however, recurrence of curvature can be seen in up to $30 \%$ of cases. ${ }^{57,58,60}$ New onset erectile dysfunction after surgery occurs in up to $20 \%$ of cases, with a risk of decreased penile sensation in up to $20 \%$ of cases as well (although this is generally transient)..$^{52,59,60}$ Additional complications from surgery include possible urethra injury in the placement of ventral sutures for dorsal curvature $(\sim 1 \%)$, hematoma formation, and infection. ${ }^{61}$

\section{Plaque excision/incision with grafting}

Plaque excision is generally considered when penile curvature is $>60^{\circ}$ or there is severe narrowing (causing a hinging). Additional consideration may be given when a plaque is large, calcified, and limits other options. ${ }^{62}$ This surgical procedure has a high rate of subsequent erectile dysfunction, and therefore, the patient must be extensively counseled regarding the risks and benefits of this procedure. ${ }^{62,63}$

Specific techniques include plaque incision and partial excision. Complete excision is generally avoided as this produces even higher rates of erectile dysfunction. ${ }^{60}$ Incision is generally performed in a modified $\mathrm{H}$ or double $\mathrm{Y}$ incision at the site of maximal curvature ${ }^{64}$ Multiple grafting options have been evaluated including dermis, tunica vaginalis, saphenous vein, crura, buccal mucosa, fascia lata, Dacron, and Teflon. ${ }^{65,66}$ Most recently, two other options have become more popular, Tutoplast (Coloplast, Fredensborg, Denmark), which is processed by human and bovine pericardium, and small intestinal submucosa graft (Surgisis ES; Cook Urologic, Bloomington, IN, USA). ${ }^{67,68}$ Pericardial grafts have been shown to have low infection rates and no contraction, although a study has cited a curvature, recurrence rate up to $44 \% .{ }^{68}$ Submucosal grafts have had good success; however, they have been linked with graft contraction in up to $25 \%$ and curvature recurrence between $37 \%$ and $75 \% .{ }^{68,69}$ Another option was recently evaluated with grafting by collagen fleece after partial excision. Major advantages of the collagen fleece that have been cited are decreased operative time, easy application, and additional hemostatic nature of the graft. In this recent study, 61 evaluated patients are grafted, a mean operative time was 94.2 minutes (range: 65-165) with straight erection achieved in $83.6 \% .^{70}$

Recovery and satisfaction rates for these procedures are good, with a number of studies showing a satisfaction rate of $\sim 75 \%-80 \%$ for both the small intestinal submucosa and the pericardial grafts..$^{60,67,68,71-77}$

\section{Penile prosthesis}

For those men who do not have adequate erections according to self-reporting during their initial evaluation or do not have an adequate erectile response during evaluation and duplex ultrasonography with injection, penile prosthesis should be the first-line therapy for the treatment of PD. Penile prosthesis placement may be accompanied by a variety of procedures to address the patient's curvature.

The first and often cited option for curvature $<30^{\circ}$ is manual modeling performed at the time of the prosthesis placement. Pressure is applied contralateral to the curvature for $60-90$ seconds, with the cylinders fully inflated. The pressure should be applied in a gradual manner to reduce the risk of injury. ${ }^{44}$ The cylinders are then even further inflated, and the curvature is reassessed, and if necessary, the modeling may be repeated to obtain the desired results.

If the degree of curvature after an attempt at modeling is still $>30^{\circ}$ or the curvature is felt to be severe prior to the case, penile plication via the Nesbit or 16-dot plication procedure can be performed. Plication is most commonly performed with suture placement either prior to the procedure with the aid of saline infusion via a butterfly needle to determine erect curvature or after cylinder placement. Suture placement after cylinder placement generally requires brief removal of the cylinders to prevent injury of the prosthetic device.

Perito and Wilson in 2013 described the "scratch technique" through the incision of the plaque internally, passing a scalpel blade in a longitudinal fashion via the corporotomy made for the placement of the penile prosthetic. The passage of this scalpel leads to internal disruption of the plaque allowing stretching and disruption of the Peyronie's plaque. They have further supported the use of this technique in combination with penile modeling with the implant in place. ${ }^{78}$

Additionally, external incisions of the corporal body, on the side of the curvature, effectively releasing the shortened tunica may also be performed. Before incising the area, Buck's fascia is elevated to preserve the neurovascular bundles. If the defect caused by the incision is $>2 \mathrm{~cm}$, a graft should be placed over the corporal defect. ${ }^{44}$

For very large plaques, extensive corporal involvement, plaque excision, and grafting with the placement of prosthesis are often necessary. Additional procedures such as the "sliding technique" were described first in 2012, wherein grafts are placed in a ventral and dorsal fashion after ventral and dorsal incisions to the tunica albuginea. In the first three 
described cases, the patients were able to regain up to $3.2 \mathrm{~cm}$ of length. ${ }^{79}$ Additional techniques such as circumferential tunical grafting at the time of prosthesis placement have been discussed. An early report from 2012 with follow-up from 23 patients showed an average improvement in penile length of $2.8 \mathrm{~cm}$ with $90 \%$ of the patients happy with the cosmetic and functional results of this surgery. ${ }^{80}$

In those patients counseled to undergo surgery, an indepth discussion regarding expectations is of utmost importance. Many procedures involved the loss of length and are not reversible. ${ }^{53}$ At presentation for $\mathrm{PD}, 70-80 \%$ of men state that they have already lost penile length. ${ }^{52}$ While the goal of surgical therapy is to produce a straight penis, the penultimate goal should be to produce a functional penis that allows the patient to resume normal sexual function.

\section{Conclusion}

PD is common and likely underreported. The disease causes significant physical and psychological distress for patients. There are a wide variety of treatment options that have been used in the past. Recently, there are highly effective nonsurgical treatment options, which will likely increase patient and provider awareness as well as prevalence of the disease.

\section{Disclosure}

The authors report no conflicts of interest in this work.

\section{References}

1. Brock G, Hsu GL, Nunes L, von Heyden B, Lue TF. The anatomy of the tunica albuginea in the normal penis and Peyronie's disease. $J$ Urol. 1997; 157:276-281.

2. Devine CJ, Somers KD, Jordan SG, Schlossberg SM. Proposal: trauma as the cause of the Peyronie's lesion. J Urol. 1997;157(1):285-290. [Available from: http://www.ncbi.nlm.nih.gov/pubmed/8976281. Accessed March 8, 2015].

3. Taylor FL, Levine LA. Peyronie's disease. Urol Clin North Am. 2007;34:517-534.

4. Schwarzer U, Sommer F, Klotz T, Braun M, Reifenrath B, Engelmann U. The prevalence of Peyronie's disease: results of a large survey. BJU Int. 2001;88:727-730.

5. Lindsay MB, Schain DM, Grambsch P, Benson RC, Beard CM, Kurland LT. The incidence of Peyronie's disease in Rochester, Minnesota, 1950 through 1984. J Urol. 1991;146(4):1007-1009. Available from: http://www.ncbi.nlm.nih.gov/pubmed/1895413. Accessed March 9, 2015.

6. Dibenedetti DB, Nguyen D, Zografos L, Ziemiecki R, Zhou X. A population-based study of Peyronie's disease: prevalence and treatment patterns in the United States. Adv Urol. 2011;2011:10-13.

7. Shiraishi K, Shimabukuro T, Matsuyama H. The prevalence of Peyronie's disease in Japan: a study in men undergoing maintenance hemodialysis and routine health checks. $J$ Sex Med. 2012;9:2716-2723.

8. La Pera G, Pescatori ES, Calabrese M, et al; SIMONA Study Group. Peyronie's disease: prevalence and association with cigarette smoking. A multicenter population-based study in men aged 50-69 years. Eur Urol. 2001;40(5):525-530. [Available from:http://www.ncbi.nlm.nih. gov/pubmed/11752860. Accessed March 10, 2015].
9. Mulhall JP, Creech SD, Boorjian SA, et al. Subjective and objective analysis of the prevalence of Peyronie's disease in a population of men presenting for prostate cancer screening. J Urol. 2004;171(6 pt 1): 2350-2353. Available from: http://www.ncbi.nlm.nih.gov/ pubmed/15126819. Accessed March 7, 2015.

10. Gholami SS, Gonzalez-Cadavid NF, Lin C-S, Rajfer J, Lue TF. Peyronie's disease: a review. J Urol. 2003;169(April):1234-1241.

11. Bjekic MD, Vlajinac HD, Sipetic SB, Marinkovic JM. Risk factors for Peyronie's disease: a case-control study. BJU Int. 2006;97:570-574.

12. Kendirci M, Trost L, Sikka SC, Hellstrom WJG. Diabetes mellitus is associated with severe Peyronie's disease. BJU Int. 2007;99:383-386.

13. Rhoden EL, Riedner CE, Fuchs SC, Fuchs S, Ribeiro EP, Halmenschlager G. A cross-sectional study for the analysis of clinical, sexual and laboratory conditions associated to Peyronie's disease. J Sex Med. 2010;7(4 pt 1):1529-1537.

14. Nugteren HM, Nijman JM, de Jong IJ, van Driel MF. The association between Peyronie's and Dupuytren's disease. Int J Impot Res. 2011;23(4):142-145.

15. Carrieri MP, Serraino D, Palmiotto F, Nucci G, Sasso F. A casecontrol study on risk factors for Peyronie's disease. J Clin Epidemiol. 1998;51(6):511-515. Available from: http://www.ncbi.nlm.nih.gov/ pubmed/9636000. Accessed June 2, 2015.

16. Nelson CJ, Diblasio C, Kendirci M, Hellstrom W, Guhring P, Mulhall JP. The chronology of depression and distress in men with Peyronie's disease. J Sex Med. 2008;5(8):1985-1990.

17. Smith JF, Walsh TJ, Conti SL, Turek P, Lue T. Risk factors for emotional and relationship problems in Peyronie's disease. $J$ Sex Med. 2008;5(9):2179-2184.

18. Hellstrom WJG, Feldman R, Rosen RC, Smith T, Kaufman G, Tursi J. Bother and distress associated with Peyronie's disease: validation of the Peyronie's disease questionnaire. J Urol. 2013;190(2):627-634.

19. Mulhall JP, Schiff J, Guhring P. An analysis of the natural history of Peyronie's disease. J Urol. 2006;175:2115-2118. discussion 2118.

20. Chung E, De Young L, Brock GB. Penile duplex ultrasonography in men with Peyronie's disease: is it veno-occlusive dysfunction or poor cavernosal arterial inflow that contributes to erectile dysfunction? $J$ Sex Med. 2011;8(12):3446-3451.

21. El-Sakka AI, Hassoba HM, Pillarisetty RJ, Dahiya R, Lue TF. Peyronie's disease is associated with an increase in transforming growth factor-beta protein expression. J Urol. 1997;158(4):1391-1394.

22. Brant WO, Dean RC, Lue TF. Treatment of Peyronie's disease with oral pentoxifylline. Nat Clin Pract Urol. 2006;3(2):111-115. quiz 116.

23. Safarinejad MR, Asgari MA, Hosseini SY, Dadkhah F. A double-blind placebo-controlled study of the efficacy and safety of pentoxifylline in early chronic Peyronie's disease. BJU Int. 2010;106:240-248.

24. Smith JF, Shindel AW, Huang Y-C, et al. Pentoxifylline treatment and penile calcifications in men with Peyronie's disease. Asian J Androl. 2011;13(2):322-325.

25. Nehra A, Alterowitz R, Culkin DJ, et al; American Urological Association Education and Research, Inc. Peyronie's disease: AUA guideline. J Urol. 2015;194(3):745-753.

26. Safarinejad MR, Hosseini SY, Kolahi AA. Comparison of vitamin E and propionyl-L-carnitine, separately or in combination, in patients with early chronic Peyronie's disease: a double-blind, placebo controlled, randomized study. J Urol. 2007;178(4):1398-1403.

27. Inal T, Tokatli Z, Akand M, Ozdiler E, Yaman O. Effect of intralesional interferon-alpha $2 \mathrm{~b}$ combined with oral vitamin $\mathrm{E}$ for treatment of early stage Peyronie's disease: a randomized and prospective study. Urology. 2006;67(5):1038-1042. doi:10.1016/j.urology.2005.11.005.

28. Prieto Castro RM, Leva Vallejo ME, Regueiro Lopez JC, Anglada Curado FJ, Alvarez Kindelan J, Requena Tapia MJ. Combined treatment with vitamin $\mathrm{E}$ and colchicine in the early stages of Peyronie's disease. BJU Int. 2003;91(6):522-524.

29. Weidner W, Hauck EW, Schnitker J. Potassium paraaminobenzoate $\left(\mathrm{POTABA}^{\mathrm{TM}}\right)$ in the treatment of Peyronie's disease: a prospective, placebo-controlled, randomized study. Eur Urol. 2005;47(4):530-535. 
30. Akkus E, Carrier S, Rehman J, Breza J, Kadioglu A, Lue TF. Is colchicine effective in Peyronie's disease? A pilot study. Urology. 1994;44(2):291-295. Available from: http://www.ncbi.nlm.nih.gov/ pubmed/8048212. Accessed June 16, 2015.

31. Safarinejad MR. Therapeutic effects of colchicine in the management of Peyronie's disease: a randomized double-blind, placebo-controlled study. Int J Impot Res. 2004;16(3):238-243.

32. Teloken C, Rhoden EL, Grazziotin TM, Ros CT, Sogari PR, Souto CA. Tamoxifen versus placebo in the treatment of Peyronie's disease. $J$ Urol. 1999;162(6):2003-2005. Available from: ttp://www.ncbi.nlm.nih.gov/ pubmed/10569556. Accessed June 16, 2015.

33. Biagiotti G, Cavallini G. Acetyl- L-carnitine vs tamoxifen in the oral therapy of Peyronie's disease: a preliminary report. BJU Int. 2001;88:63-67.

34. Russell S, Steers W, McVary KT. Systematic evidence-based analysis of plaque injection therapy for Peyronie's disease. Eur Urol. 2007;51(3):640-647.

35. Safarinejad MR. Safety and efficacy of coenzyme Q10 supplementation in early chronic Peyronie's disease: a double-blind, placebo-controlled randomized study. Int J Impot Res. 2010;22(5):298-309.

36. Lacy GL, Adams DM, Hellstrom WJG. Intralesional interferonalpha- $2 \mathrm{~b}$ for the treatment of Peyronie's disease. Int $J$ Impot Res. 2002;14(5):336-339.

37. Hellstrom WJG, Kendirci M, Matern R, et al. Single-blind, multicenter, placebo controlled, parallel study to assess the safety and efficacy of intralesional interferon alpha-2B for minimally invasive treatment for Peyronie's disease. J Urol. 2006;176(1):394-398.

38. Trost LW, Ates E, Powers M, Sikka S, Hellstrom WJG. Outcomes of intralesional interferon-a2B for the treatment of Peyronie disease. J Urol. 2013;190(6):2194-2199.

39. Favilla V, Russo GI, Privitera S, et al. Combination of intralesional verapamil and oral antioxidants for Peyronie's disease: a prospective, randomised controlled study. Andrologia. 2013;46(8):936-942.

40. Roth M, Eickelberg O, Kohler E, Erne P, Block LH. Ca2+ channel blockers modulate metabolism of collagens within the extracellular matrix. Proc Natl Acad Sci U S A. 1996;93(11):5478-5482. Available from: http://www.pubmedcentral.nih.gov/articlerender.fcgi?artid=39271\& tool=pmcentrez\&rendertype=abstract. Accessed June 16, 2015.

41. Mulhall JP, Creech SD, Boorjian SA, et al. Subjective and objective analysis of the prevalence of Peyronie's disease in a population of men presenting for prostate cancer screening. J Urol. 2004. doi:10.1097/01. ju.0000127744.18878.f1.

42. Pendleton C, Wang R. Peyronie's disease: current therapy. Transl Androl Urol. 2013;2(3):15-23.

43. Rehman J, Benet A, Melman A. Use of intralesional verapamil to dissolve Peyronie's disease plaque: a long-term single-blind study. Urology. 1998;51(4):620-626.

44. Gelbard M, Goldstein I, Hellstrom WJG, et al. Clinical efficacy, safety and tolerability of collagenase Clostridium histolyticum for the treatment of Peyronie disease in 2 large double-blind, randomized, placebo controlled phase 3 studies. J Urol. 2013;190(1):199-207.

45. Levine LA, Cuzin B, Mark S, et al. Clinical safety and effectiveness of collagenase Clostridium histolyticum injection in patients with Peyronie's disease: a phase 3 open-label study. J Sex Med. 2015;12(1):248-258

46. Levine LA, Newell M, Taylor FL. Penile traction therapy for treatment of Peyronie's disease: a single-center pilot study. J Sex Med. 2008;5(6):1468-1473.

47. Yafi F A, Pinsky MR, Stewart C, et al. The Effect of Duration of Penile Traction Therapy in Patients Undergoing Intralesional Injection Therapy for Peyronie's Disease. J Urol. 2015;(6):1-5.

48. Raheem AA, Garaffa G, Raheem TA, et al. The role of vacuum pump therapy to mechanically straighten the penis in Peyronie's disease. $B J U$ Int. 2010;106(8):1178-1180.

49. Greenfield JM, Shah SJ, Levine LA. Verapamil versus saline in electromotive drug administration for Peyronie's disease: a double-blind, placebo controlled trial. J Urol. 2007;177(3):972-975.
50. Hauck EW, Mueller UO, Bschleipfer T, Schmelz HU, Diemer T, Weidner W. Extracorporeal shock wave therapy for Peyronie's disease: exploratory meta-analysis of clinical trials. $J$ Urol. 2004;171(2 pt 1): 740-745.

51. Palmieri A, Imbimbo C, Longo N, et al. A first prospective, randomized, double-blind, placebo-controlled clinical trial evaluating extracorporeal shock wave therapy for the treatment of Peyronie's disease. Eur Urol. 2009;56(2):363-370.

52. Ralph D, Gonzalez-Cadavid N, Mirone V, et al. The management of Peyronie's disease: EVIDENCE-based 2010 guidelines. J Sex Med. 2010;7(7):2359-2374.

53. Levine LA, Larsen SM. Surgery for Peyronie's disease. Asian J Androl. 2012;15(1):27-34.

54. Ohebshalom M, Mulhall J, Guhring P, Parker M. Measurement of penile curvature in Peyronie's disease patients: comparison of three methods. J Sex Med. 2007;4(1):199-203.

55. Andrews HO, Al-Akraa M, Pryor JP, Ralph DJ. The Nesbit operation for congenital curvature of the penis. Int J Impot Res. 1999;11(3):119-122. Available from: http://www.ncbi.nlm.nih.gov/pubmed/10404279. Accessed June 16, 2015.

56. Yachia D. Modified corporoplasty for the treatment of penile curvature. J Urol. 1990;143(1):80-82. Available from: http://www.ncbi.nlm.nih. gov/pubmed/2294269. Accessed June 16, 2015.

57. Gholami SS, Lue TF. Correction of penile curvature using the 16-dot plication technique: a review of 132 patients. J Urol. 2002;167(5):2066-2069.

58. Brant WO, Bella AJ, Lue TF. 16-Dot procedure for penile curvature. J Sex Med. 2007;4(2):277-280.

59. Greenfield JM, Lucas S, Levine LA. Factors affecting the loss of length associated with tunica albuginea plication for correction of penile curvature. J Urol. 2006;175(1):238-241.

60. Taylor FL, Levine LA. Surgical correction of Peyronie's disease via tunica albuginea plication or partial plaque excision with pericardial graft: long-term follow up. J Sex Med. 2008;5(9): 2221-2228

61. Tornehl CK, Carson CC. Surgical alternatives for treating Peyronie's disease. BJU Int. 2004;94(6):774-783.

62. Taylor FL, Abern MR, Levine LA. Predicting erectile dysfunction following surgical correction of Peyronie's disease without inflatable penile prosthesis placement: vascular assessment and preoperative risk factors. J Sex Med. 2012;9(1):296-301.

63. Cormio L, Zucchi A, Lorusso F, et al. Surgical treatment of Peyronie's disease by plaque incision and grafting with buccal mucosa. Eur Urol. 2009;55(6):1469-1476.

64. Gelbard MK. Relaxing incisions in the correction of penile deformity due to Peyronie's disease. J Urol. 1995;154(4):1457-1460. Available from: http://www.ncbi.nlm.nih.gov/pubmed/7658558. Accessed June 16, 2015.

65. Kadioglu A, Sanli O, Akman T, Ersay A, Guven S, Mammadov F. Graft materials in Peyronie's disease surgery: a comprehensive review. $J$ Sex Med. 2007;4(3):581-595.

66. Teloken C, Grazziotin T, Rhoden E, et al. Penile straightening with crural graft of the corpus cavernosum. $J$ Urol. 2000;164(1): $107-108$.

67. Knoll LD. Use of small intestinal submucosa graft for the surgical management of Peyronie's disease. J Urol. 2007;178(6):2474-2478. discussion 2478 .

68. Chun JL, McGregor A, Krishnan R, Carson CC. A comparison of dermal and cadaveric pericardial grafts in the modified Horton-Devine procedure for Peyronie's disease. J Urol. 2001;166(1):185-188.

69. John T, Bandi G, Santucci R. Porcine small intestinal submucosa is not an ideal graft material for Peyronie's disease surgery. $J$ Urol. 2006;176(3):1025-1029.

70. Hatzichristodoulou G, Gschwend JE, Lahme S. Surgical therapy of Peyronie's disease by partial plaque excision and grafting with collagen fleece: feasibility study of a new technique. Int J Impot Res. 2013;25(5): $183-187$. 
71. Usta MF, Bivalacqua TJ, Sanabria J, Koksal IT, Moparty K, Hellstrom WJG. Patient and partner satisfaction and long-term results after surgical treatment for Peyronie's disease. Urology. 2003;62(1): 105-109.

72. Kovac JR, Brock GB. Surgical outcomes and patient satisfaction after dermal, pericardial, and small intestinal submucosal grafting for Peyronie's disease. J Sex Med. 2007;4(5):1500-1508.

73. Leungwattanakij S, Bivalacqua TJ, Reddy S, Hellstrom WJ. Long-term follow-up on use of pericardial graft in the surgical management of Peyronie's disease. Int J Impot Res. 2001;13(3):183-186. Available from: http://www.ncbi.nlm.nih.gov/pubmed/11525318. Accessed June 16, 2015.

74. Levine LA, Estrada CR. Human cadaveric pericardial graft for the surgical correction of Peyronie's disease. J Urol. 2003;170(6 pt 1): 2359-2362.

75. Breyer BN, Brant WO, Garcia MM, Bella AJ, Lue TF. Complications of porcine small intestine submucosa graft for Peyronie's disease. J Urol. 2007;177(2):589-591.

76. Staerman F, Pierrevelcin J, Ripert T, Menard J. Medium-term follow-up of plaque incision and porcine small intestinal submucosal grafting for Peyronie's disease. Int J Impot Res. 2010;22(6):343-348.
77. Lee EW, Shindel AW, Brandes SB. Small intestinal submucosa for patch grafting after plaque incision in the treatment of Peyronie's disease. Int Braz J Urol. 2008;34(2):191-196. discussion 197. Available from: http:// www.ncbi.nlm.nih.gov/pubmed/18462517. Accessed June 16, 2015.

78. Perito P, Wilson S. The Peyronie's plaque "scratch": an adjunct to modeling. J Sex Med. 2013;10(5):1194-1197. [Available from: http:// www.ncbi.nlm.nih.gov/pubmed/23750353. Accessed December 21, 2015].

79. Rolle L, Ceruti C, Timpano M, et al. A new, innovative, lengthening surgical procedure for Peyronie's disease by penile prosthesis implantation with double dorsal-ventral patch graft: the "sliding technique". J Sex Med. 2012;9(9):2389-2395.

80. Sansalone S, Garaffa G, Djinovic R, et al. Simultaneous penile lengthening and penile prosthesis implantation in patients with Peyronie's disease, refractory erectile dysfunction, and severe penile shortening. J Sex Med. 2012;9(1):316-321.

\section{Publish your work in this journal}

Research and Reports in Urology is an international, peer-reviewed, open access journal publishing original research, reports, editorials, reviews and commentaries on all aspects of adult and pediatric urology in the clinic and laboratory including the following topics: Pathology, pathophysiology of urological disease; Investigation and treatment of

\section{Dovepress}

urological disease; Pharmacology of drugs used for the treatment of urological disease. The manuscript management system is completely online and includes a very quick and fair peer-review system, which is all easy to use. Visit http://www.dovepress.com/testimonials.php to read real quotes from published authors.

Submit your manuscript here: http://www.dovepress.com/research-and-reports-in-urology-journal 